\title{
Testando Teorias Alternativas sobre a Estrutura de Capital nas Empresas Brasileiras
}

\section{Testing Alternative Theories on the Capital Structure of Brazilian Firms}

Otávio Ribeiro de Medeiros*

Ph.D. em Economia pela Universidade de Southampton, Reino Unido. Professor Titular do Programa de Pós-Graduação em Administração e do Programa de Pós-Graduação em Ciências Contábeis da UnB, Brasília/DF, Brasil.

Cecílio Elias Daher

Mestre em Ciências Contábeis pela UnB.

Professor da Faculdade de Administração, da Unidade de Ciências Sócio-Econômicas e Humanas da UEG, Anápolis/GO, Brasil.

*Endereço: Campus Darcy Ribeiro, ICC Ala Norte, Subsolo, Módulo 25, Brasília/DF, 70910-970.E-mail: otavio@unb.br 


\section{Resumo}

O artigo documenta resultados de testes empíricos que envolvem dois modelos aplicados a estruturas de capital de empresas brasileiras. Os modelos testados foram desenvolvidos sob as duas principais teorias que competem entre si na literatura acadêmica pela determinação da estrutura de capital das empresas: a Static Tradeoffe a Pecking Order. A metodologia envolve a utilização de técnicas econométricas com dados em painel (panel data), buscando estabelecer qual das duas teorias possui maior poder explanatório para a amostra de empresas brasileiras. A análise utilizou três tipos de modelos: coeficientes comuns, efeitos fixos e efeitos aleatórios. Foram utilizados ainda diversos testes estatísticos para confirmar a robustez dos resultados. A amostra utilizada compreende empresas não-financeiras listadas nas bolsas de valores de São Paulo (BOVESPA e SOMA) no período de 1995 a 2002. A análise dos resultados encontrados levou à conclusão de que a chamada teoria Pecking Order, em sua forma semiforte, é a que melhor explicou a determinação da estrutura de capital das empresas brasileiras.

Palavras-chave: estrutura de capital; empresas brasileiras; static tradeoff; pecking order.

\section{ABSTRACT}

The paper documents results of empírical tests involving two models applied to the capital structure of Brasilian firms. The models tested were developed under the two theories competing for the determination of the capital structure of firms in the academic literature: the Static Tradeoff Theory and the Pecking Order Theory. The methodology involves the utilization of panel-data econometric techniques, aiming to establish which of the two theories has higher explanatory power for the Brazilian firms. The analisis utilized three types of models: common coeficients, fixed effects, and random effects. Additional statistical tests were also employed to confirm the robustness of results. The sample consists of non-financial firms listed in the Sao Paulo stock exchanges (BOVESPA and SOMA) from 1995 to 2002. The analysis of the results obtained led to the conclusion that the Pecking Order Theory in its semi-strong form provides the best explanation for the capital structure of Brazilian firms.

Key words: capital structure; Brazilian firms; static tradeoff; pecking order. 


\section{INTRODUÇÃO}

Duas correntes teóricas competem entre si pela explicação da estrutura de capital das empresas: a Static Tradeoff Theory (STT), que afirma que as empresas perseguem uma estrutura de capital pré-estabelecida, e a Pecking Order Theory (POT), pela qual o que determina o endividamento das empresas é a diferença entre o fluxo de caixa gerado internamente e o déficit financeiro. Outras teorias, tais com as baseadas nos custos de agência e na assimetria de informações, são consideradas subcorrentes da STT (Frank \& Goyal, 2003a). Tendo em vista que tais teorias foram desenvolvidas no contexto da economia norte-americana, parece oportuno investigar se elas seriam válidas para a realidade brasileira. No Brasil, há poucos artigos sobre estrutura de capital (Famá \& Melher, 1999; Famá \& Grava, 2000; Fama, Barros, \& Silveira, 2001).

O objetivo do presente artigo é estabelecer empiricamente qual das duas citadas teorias melhor explica a estrutura de capital das empresas brasileiras. Para tanto, são testados os modelos propostos por Rajan e Zingales (1995), para a STT, e o modelo proposto por Frank e Goyal (2003b), para a POT. A relevância do trabalho está na importância do tema e na utilização da metodologia de panel data, só recentemente utilizada em estudos sobre estrutura de capital em outros países. No restante do trabalho, a segunda seção apresenta a fundamentação teórica e resultados anteriores; a terceira, os modelos testados; a quarta, a metodologia; a quinta, a análise dos resultados; e a sexta, as conclusões.

\section{FundamentaÇão Teórica}

\section{Static Trade-off Theory}

Myers (1984) afirma que há duas correntes na teoria da estrutura de capital. A primeira ele chama de Static Tradeoff Theory (STT), que supõe que a empresa possui uma meta de endividamento e caminha em sua direção. Tal meta seria estabelecida como resultado do confronto entre o custo e o benefício da dívida, onde o custo de falência se contraporia ao benefício fiscal. Pelo lado da STT, vários testes foram realizados na tentativa de encontrar possíveis determinantes da meta de endividamento. Titman e Wessels (1988) testaram diversas variáveis, tais como composição dos ativos, escudos fiscais que não os provenientes de 
dívidas, oportunidades de crescimento, diferenciação dos produtos, segmento industrial, tamanho, volatilidade dos lucros e lucratividade. Apenas diferenciação e lucratividade explicaram baixos níveis de endividamento, enquanto as outras variáveis não explicaram as estruturas escolhidas. $\mathrm{O}$ tamanho definiu a escolha entre endividamento de curto e longo prazo, já que empresas menores têm maior dificuldade em conseguir recursos de longo prazo. Ross (1977) introduziu os custos de falência e a sinalização assimétrica ao mercado. Devido ao alto custo de falência, os investidores tomariam como sinal de qualidade o nível de endividamento das empresas, de modo diretamente proporcional. Marsh (1982), além de concluir que as empresas se comportam de acordo com a STT, encontrou correlação entre as estruturas escolhidas e tamanho, risco de falência e composição de ativos.

\section{Pecking Order Theory}

A segunda teoria é a Pecking Order Theory (POT), pela qual toda empresa segue uma sequiência hierárquica, ao estabelecer sua estrutura de capital. Inicialmente, a empresa daria preferência ao financiamento interno. Caso necessite de financiamento externo, a seqüência lógica seria a da emissão de debêntures e títulos conversíveis, antes de optar pela emissão de ações. A POT (Myers, 1984; Myers \& Majluf, 1984) sustenta que empresas mais lucrativas são naturalmente menos endividadas, já que elas podem financiar seus novos projetos sem ter que se endividar ou emitir ações. A relutância na emissão de novas ações deve-se principalmente à sua subprecificação das ações pelo mercado. A subprecificação seria devida à menor informação detida pelos investidores potenciais em relação aos executivos sobre os fluxos esperados pelos ativos da empresa. Cientes de possuírem menor grau de informação, os investidores infeririam que os executivos emitiriam ações apenas quando o preço destas estivesse superavaliado. Conseqüentemente, os preços das ações seriam estabelecidos pelo mercado com deságio. A subprecificação levaria ao subinvestimento, já que, caso ocorresse a emissão de ações a preços considerados desfavoráveis para os acionistas correntes, haveria uma tendência de transferência de riqueza dos investidores antigos para os novos. Esse problema poderia ser contornado, caso as empresas utilizassem recursos gerados internamente, como lucros retidos. O motivo para a hierarquia da POT está na assimetria de informações entre os gestores e os novos acionistas. Esta assimetria levaria a empresa à perda de valor para os acionistas atuais caso decidisse pela nova emissão, já que os novos projetos não seriam corretamente avaliados pelo mercado, acarretando uma subavaliação das novas ações e a conseqüente transferência de riqueza dos acionistas antigos para os novos. Watson e Wilson (2002) admitem ainda outra razão, além da assimetria de informações: caso 
não haja condições de avaliação efetiva do risco, monitoração do negócio financiado e capacidade de intervenção, os provedores de crédito externo só estariam dispostos a investir a taxas de juros mais elevadas. A POT admite duas formas: a forma forte e a semiforte ou fraca (Chirinko \& Singha, 2000). Sob a forma forte, as empresas nunca recorrem à emissão de ações, financiandose exclusivamente com recursos internos e endividamento. A forma semiforte admite certo nível de emissão de ações, sendo considerada como mais plausível. A POT não rejeita inteiramente a emissão de novas ações. Ela poderia ocorrer em duas situações específicas, sem contrariar a teoria. A primeira é quando a empresa precisa de reserva financeira para eventos futuros ainda não previstos (Frank \& Goyal, 2003b; Myers, 1984; Myers \& Majluf, 1984; Shyam-Sunder \& Myers, 1999); a segunda, quando a assimetria de informações deixa de existir momentaneamente, por alguma razão, levando a empresa a aproveitar para emitir novas ações a um preço justo (Myers 1984). Para Fama e French (2002), haveria uma possibilidade de as empresas recorrerem à emissão de novas ações sem ir de encontro à POT. Isso aconteceria quando as empresas antecipassem que num futuro próximo iriam necessitar de novos financiamentos externos para viabilizar a execução de novos projetos. Caso essa necessidade prevista ficasse inviabilizada por uma projeção de endividamento acima de sua capacidade, as empresas emitiriam hoje novas ações para que tivessem condições de se endividarem mais no futuro. O resultado encontrado por Frank e Goyal (2003b), onde empresas menores tenderiam a emitir mais ações que as maiores, concluindo que a POT não se aplicaria a elas, é improvável que ocorra no Brasil, pelas características do mercado de ações local. Aqui, empresas menores dificilmente emitem ações, pelos elevados custos e também pela pouca liquidez que teriam no mercado.

\section{POT x STT: Análise Comparativa}

Apesar de convergirem em alguns pontos, a SST e a POT divergem em seus preceitos básicos. Recentemente, uma série de estudos foi realizada, confrontando as duas teorias (Fama \& French, 2002, 2003; Frank \& Goyal, 2003a, 2003b; Lemmon \& Zender, 2002; Sogorb-Mira \& López-Gracia, 2002). Como a POT estabelece que a subscrição de novas ações somente acontece como último recurso e que a forma preferencial de financiamento do déficit financeiro se dá por meio de lucros retidos, há grande ponto de divergência entre as duas correntes. Para a STT, maiores lucros levam a maior endividamento, devido ao escudo fiscal proporcionado pelos juros. Isto é exatamente o oposto do que a POT sustenta; para ela maiores lucros levam à diminuição do endividamento, já que esses lucros, caso não sejam distribuídos, se tornam a melhor fonte de geração de recursos para cobrir o déficit financeiro da empresa. 
O pagamento de dividendos pode ser outro motivo de divergência entre as duas teorias, dependendo do autor consultado. De acordo com Frank e Goyal (2003a), para a STT, os dividendos também podem mitigar conflitos de agência, estando, portanto, negativamente relacionados com o endividamento, já que diminui a necessidade de se usar dívidas para equacionar este conflito. A POT prevê uma relação direta entre endividamento e pagamento de dividendos, já que esses compõem o déficit financeiro da empresa. Fama e French (2002), afirmam que ambas as correntes consideram os dividendos como diretamente relacionados com o endividamento. O efeito dos juros é outro ponto de discordância. Para Frank e Goyal (2003a), um aumento nas taxas de juros poderia levar à emissão de ações, já que juros maiores levam a empresa a atingir sua capacidade de endividamento de modo mais rápido. Assim, taxa de juros e endividamento seriam negativamente relacionados. A relação entre endividamento e taxa de juros sob a STT se dá de forma indireta. Um aumento nas taxas de juros leva à diminuição no valor tanto das ações quanto das dívidas de longo prazo existentes. Ocorre que a diminuição no valor das ações é mais acentuada que das dívidas, levando ao aumento da proporção entre capital próprio e de terceiros. Para Frank e Goyal (2003b), dentre as variáveis convencionais, discutidas posteriormente, a tangibilidade dos ativos é o fator mais importante para se optar por uma ou outra teoria. O motivo é que, ao contrário da lucratividade, que pode ser vista como proxy para oportunidades de crescimento (neste caso, o sinal poderia ser o mesmo para ambas as teorias: negativo), a tangibilidade dos ativos não oferece dupla interpretação e o sinal indicaria a superioridade explanatória de uma teoria sobre a outra.

\section{Os Modelos}

\section{Modelo Rajan-Zingales}

A modelagem da STT utilizada no presente artigo baseia-se na especificação de Harris e Raviv (1991), testada posteriormente por Rajan e Zingales (1995). A STT pressupõe uma tendência de as empresas buscarem nível ótimo de endividamento, o qual seria atingido, caso não houvesse custos de transação nem assimetria de informações. $O$ índice-meta de endividamento $\left(\mathrm{D}^{*}{ }_{\mathrm{it}}\right)$ em algum momento seria igual ao índice de endividamento observado $\left(\mathrm{D}_{\mathrm{it}}\right)$, o que pode ser representado pelo modelo de ajustamento parcial abaixo.

$D_{i t}-D_{i t-1}=\lambda_{i t}\left(D_{i t}^{*}-D_{i t-1}\right)$

onde $\lambda_{\text {it }}$ é a velocidade de ajuste (Sogorb-Mira \& López-Gracia, 2002). 
O índice-meta de endividamento $\mathrm{D}$ *it, por sua vez, pode ser expresso como

$D_{i t}^{*}=a+b_{v}^{\prime} V_{i t}+c_{i}+c_{t}+e_{i t}$

onde $V$ é o vetor das variáveis explanatórias, $b_{v}$ o vetor dos coeficientes angulares, $c_{i}$ representa os efeitos individuais e não observáveis de cada empresa, $c_{t}$ representa os efeitos temporais e $e_{i t}$ é o termo errático. Como fatores individuais específicos podem ser citados motivação e treinamento da equipe, atitude perante o risco, barreiras de entrada etc. Os efeitos temporais dizem respeito à conjuntura macroeconômica. Definindo-se $\beta_{\mathrm{D}}$ como $\left(1-\lambda_{\mathrm{it}}\right) \mathrm{e}$ $\delta$ como o próprio $\lambda_{\mathrm{it}}$, combinando as equações [1] e [2] e rearranjando os termos, obtém-se:

$$
D_{i t}=\delta+\beta_{D} D_{i t-1}+\beta_{v}^{\prime} V+\eta_{i}+\eta_{t}+\varepsilon_{i t}
$$

onde os subscritos representam a empresa $i$ na data $t, D_{\text {it }}$ o índice de endividamento, $D_{\mathrm{it}-1}$ o índice de endividamento defasado em 1 período, $\eta_{i}=\lambda$ ${ }_{i t} \times c_{i}, \eta_{t}=\lambda_{i t} \times c_{t}$, e $\varepsilon_{i t}=\lambda_{i t} \times e_{i t}$

No modelo de Rajan e Zingales (1995), a equação [3] assume a forma

$$
D_{i t}=\alpha+\beta_{T} T_{i t}+\beta_{M B V} M B V_{i t}+\beta_{L S} L S_{i t}+\beta_{L C R} L C R_{i t}+\varepsilon_{i t}
$$

onde $D_{\text {it }}$ é o endividamento (alavancagem), $T$ a tangibilidade dos ativos, $\mathrm{MBV}_{\text {it }}$ o índice Valor de Mercado sobre Valor Patrimonial, $\mathrm{LS}_{\text {it }}$ o logaritmo natural das vendas e $\mathrm{LCR}_{\mathrm{it}}$ a lucratividade.

Quanto à tangibilidade dos ativos $T$, espera-se que empresas com ativos mais tangíveis apresentem maior nível de endividamento. O motivo é a possibilidade de estes ativos serem utilizados como garantia para empréstimos. A relação valor de mercado sobre valor patrimonial (MBV) é uma proxy para oportunidades de crescimento (Frank \& Goyal, 2003a, 2003b; Rajan \& Zingales, 1995; Titman \& Wessels, 1988), podendo capturar o momento em que as ações estão valorizadas, o que torna interessante a emissão de novas ações (Rajan \& Zingales, 1995), bem como o maior risco de estresse financeiro a que as empresas estão expostas (Rajan \& Zingales, 1995). Espera-se que empresas com maiores oportunidades de crescimento tenham nível de endividamento mais baixo, por dois motivos principais. Primeiro, o peso das dívidas pode levá-las a ter que diminuir a velocidade com que esperavam crescer (Myers, 1977). Além disto, estas empresas geram maior percepção de risco, forçando-as a trabalhar com maior volume de capital próprio (Rajan \& Zingales, 1995). No sentido oposto, espera-se que firmas com menores oportunidades de crescimento tenham maior endividamento. De acordo com Jensen e Meckling (1976), empresas com poucas oportunidades de 
crescimento tendem a gerar maior volume de fluxo de caixa livre. Estas empresas são normalmente empresas atuantes em setores mais maduros e geradoras de fluxos de caixa livres substanciais. Por terem poucas possibilidades de onde aplicar os recursos, os gerentes destas empresas poderiam conceder privilégios a si próprios, o que vai de encontro ao interesse dos acionistas. Para minorar esses problemas de agência, as empresas emitiriam mais dívida, já que a obrigação do pagamento das dívidas levaria os gerentes a serem mais cuidadosos com os recursos da empresa e a não os utilizarem em causa própria.

Outra variável explanatória é o logaritmo natural das vendas (LS), utilizada como proxy para o tamanho das empresas. Titman e Wessels (1988) justificam o uso desta variável, porque, caso exista um efeito do tamanho da empresa sobre o endividamento, ele seria maior sobre as empresas muito pequenas. Empresas maiores tendem a ser mais diversificadas e apresentarem menor risco de falência, podendo, portanto, carregar maior endividamento.

A lucratividade (LCR) é grande motivo de discórdia entre as duas correntes. Para a STT, quanto maior a lucratividade das empresas, mais elas teriam motivos para recorrerem ao endividamento e com isso tentar diminuir a carga tributária, devido à dedutibilidade dos juros do lucro tributável. A POT pressupõe que lucros maiores levam à formação da principal fonte à qual recorrem as empresas para cobrirem seu déficit financeiro: os lucros retidos. Assim, a STT espera uma relação positiva entre a lucratividade e alavancagem, enquanto a POT espera o oposto.

\section{Modelo Frank-Goyal}

Nesse modelo, a variação no endividamento $(\Delta D)$ é função de uma única variável, o déficit em fundos $(D E F)$, que é a diferença entre os investimentos realizados pela empresa e a geração de caixa, isto é:

$$
D E F_{i t}=D I V_{i t}+I_{i t}+\Delta W_{i t}-C_{i t}=\Delta D_{i t}+\Delta E_{i t}
$$

onde $D E F_{i t}$ é o déficit financeiro; $D I V_{i t}$ são os dividendos pagos; $\mathrm{I}_{\mathrm{it}}$ são os investimentos líquidos em ativos fixos; $\Delta \mathrm{W}_{\mathrm{it}}$ é a variação do capital circulante líquido; $\mathrm{C}_{\mathrm{it}}$ é o caixa gerado após juros e impostos; $\Delta \mathrm{D}_{\mathrm{it}}$ é a dívida líquida emitida e $\Delta \mathrm{E}_{\mathrm{it}}$ são as emissões líquidas de ações. Os subscritos referem-se à empresa $i$ no ano $t$. A equação básica testada foi

$$
\Delta D_{i t}=a+b D E F_{i t}+e_{i t}
$$

onde $\mathrm{e}_{\mathrm{it}}$ é o termo errático. Espera-se encontrar $a=0, b=1 \mathrm{e}$ um $\mathrm{R}^{2}$ elevado, no modo forte da POT. A POT pressupõe que empresas com maior assimetria 
de informações, como empresas pequenas e com crescimento elevado, estejam mais sujeitas a ela. O resultado encontrado por Frank e Goyal (2003b) foi exatamente o oposto. As maiores empresas foram as que apresentaram maior propensão a seguirem a POT, no primeiro período considerado, fato que foi diminuindo com o passar dos anos. As conclusões a que chegaram Frank e Goyal (2003b), foram explicadas por Lemmon e Zender (2002), quando estes acrescentaram o fator "capacidade de crédito", ao modelo. Com as empresas tendo sua capacidade de crédito quase tomada e sem que haja geração de recursos internos suficientes para cobrir o déficit financeiro, não lhes restaria outra opção a não ser a emissão de ações. Portanto, o fato de uma empresa emitir ações não invalida a POT, dada sua capacidade de crédito. Fama e French (2003) não vêem no resultado obtido por Frank e Goyal (2003b) um indício de que as empresas não seguem a POT. Para esses autores, a POT permite que empresas com grandes oportunidades de crescimento, mesmo que tenham nível baixo de endividamento, reservem sua capacidade de endividamento para momentos mais necessários e financiem seu crescimento rápido inicial com emissão de ações.

Como o déficit (DEF) é dado por

$$
D E F_{i t}=D I V_{i t}+I_{i t}+\Delta W_{i t}-C_{i t}
$$

pode-se testar também a especificação com as variáveis que compõem o déficit de forma desagregada. A equação é dada por:

$$
\Delta D_{i t}=a+b D I V_{i t}+b I_{i t}+b \Delta W_{i t}-b C_{i t}+e_{i t}
$$

Espera-se encontrar um coeficiente $b$ bem próximo da unidade e a constante igual a zero. Um coeficiente próximo, mas menor que a unidade, indica a forma semiforte da POT. Um coeficiente igual a 1 indica a forma forte. Ao se testar a relação entre a variação do endividamento líquido e os componentes do déficit em fundos de maneira desagregada (Eq. 8), é de se esperar também que todos os coeficientes sejam próximos à unidade. Em resumo, testar empiricamente a validade da POT em sua forma forte significa testar $\mathrm{H}_{0}: a=0$ e $b=1$, enquanto na forma semiforte, significa testar $\mathrm{H}_{0}: b<1$, porém próximo de 1 (por exemplo, $\mathrm{H}_{0}: b=0,8$ ). A rejeição de $\mathrm{H}_{0}$ na forma forte e na forma semiforte implica na rejeição da POT. Quanto à causalidade da variável $D E F$, Shyam-Sunder e Myers (1999) consideram-na exógena. A exogeneidade ocorre se pelo menos dois dos componentes do déficit forem exógenos. É o caso dos dividendos e dos investimentos, variáveis definidas em assembléias de acionistas, no início de cada ano, para períodos de até cinco anos, sendo independentes dos demais números gerados internamente. 
A análise em panel data permite capturar o comportamento das variáveis tanto na dimensão temporal quanto na espacial. Existem três tipos de modelos analíticos de panel data: o de coeficiente constante, o de efeitos fixos e o de efeitos aleatórios (Greene, 2003, pp. 285-287). O modelo de coeficientes constantes pressupõe que tanto o intercepto quanto as inclinações não variam. Este modelo também é chamado de pooled regression. O modelo de efeitos fixos individuais pressupõe que as inclinações se mantêm, mas os interceptos são diferentes para cada unidade. Nesse caso, não há efeitos temporais influenciando a regressão, mas apenas individuais. Estes efeitos podem ser observáveis ou não e estão normalmente correlacionados com os regressores, ou seja, são endógenos (Baltagi, 2001, p. 20). O modelo de efeitos aleatórios pressupõe que, caso haja efeitos que não façam parte do modelo, estes são exógenos e não correlacionados com os regressores. Ao se definir por um dos modelos de panel data, o teste do multiplicador de Lagrange de Breusch e Pagan (1980) é determinante. Esta estatística é baseada na correlação dos resíduos e tem distribuição Qui-quadrada. Caso os valores obtidos para a estatística LM sejam superiores ao valor crítico, rejeita-se a hipótese nula de que o modelo sem efeitos é verdadeiro. Além disso, é preciso que seja feita a escolha sobre qual modelo (fixo ou aleatório) melhor explica a relação analisada. O teste de Hausman (1978) é usado para testar a ortogonalidade entre os efeitos aleatórios e os regressores e com isto possibilitar a definição por um ou outro modelo. A hipótese nula é de que não há correlação. Caso a hipótese nula não seja rejeitada, o modelo aleatório será considerado o que melhor explica a relação.

Um dos pressupostos da regressão linear é que os resíduos não sofram de autocorrelação nem heteroscedasticidade (Greene, 2003). Como a amostra analisada é composta por empresas bastante diversas entre si, não somente em termos de atividade, mas também em termos de tamanho, é de se esperar que o pressuposto de homoscedasticidade não ocorra. Assim, foi utilizado o estimador de White (1980), consistente sob condições de heterocedasticidade, o que proporciona estatísticas $t$ não enviesadas. Não foram realizados testes de raízes unitárias para testar a estacionariedade de séries temporais, porquanto, conforme Baltagi (2001, pp. 233-236), tais testes somente se justificam para macropainéis: séries temporais que tendem ao infinito, tanto quanto os cortes transversais. No caso atual de micropainéis (séries temporais pequenas enquanto os cortes temporais tendem ao infinito), tais testes não se fazem necessários.

\section{Resultados Esperados: STT x POT}

Tangibilidade dos Ativos: o sinal esperado para essa variável é positivo para a STT, já que os ativos fixos servem como garantia de novos empréstimos, favorecendo o endividamento. Quanto à POT, Harris e Raviv (1991) 
argumentaram que empresas com poucos ativos fixos teriam maiores problemas de assimetria de informações, levando-as a se endividarem mais, já que a emissão de ações somente seria possível com subprecificação delas. Já empresas com elevados valores nesta variável normalmente são empresas maiores e que conseguem emitir novas ações a preços justos, não necessitando recorrer à emissão de dívidas para financiarem novos investimentos. De acordo com estes autores, a relação esperada entre a tangibilidade dos ativos e o endividamento seria, portanto, negativa.

Valor de mercado sobre Valor Patrimonial. A relação esperada dessa variável com o endividamento é negativa para a STT, visto que níveis elevados de endividamento poderiam comprometer o crescimento futuro esperado. Para a POT, existem duas possibilidades para o sinal desta variável: por um lado, firmas com grandes oportunidades de crescimento tenderiam a manter seu nível de endividamento baixo, para não prejudicarem sua capacidade de crédito, quando ela se fizer necessária (sinal negativo). Por outro lado, este crescimento requer investimentos que são feitos normalmente com a contração de novas dívidas (sinal positivo). Fama e French (2002) chamaram estas duas possibilidades de versão complexa e simples da POT, respectivamente. O presente trabalho considerou apenas a versão complexa da POT (sinal negativo).

Logaritmo Natural das Vendas: a STT define que, quanto maior a empresa, maior a possibilidade de ela se endividar, apresentando, portanto uma relação positiva entre o endividamento e essa variável. Um dos motivos é que, quanto maior a empresa, menor a possibilidade de falência e menos voláteis são seus números. Empresas maiores são também mais diversificadas, com melhor reputação e com menores custos de assimetria de informações (Frank \& Goyal, 2003a). Quanto à POT, a opinião dos vários autores é divergente. Frank e Goyal (2003b) comentam que esta relação poderia ser negativa, já que quanto maior a empresa, maiores suas instalações e mais sujeita aos efeitos da seleção adversa preconizada por Myers e Majluf (1984); caso esta variável esteja mais correlacionada com o lucro do que com o tamanho, a relação é definitivamente negativa. Esta opinião é compartilhada também por Harris e Raviv (1991). Por outro lado, a assimetria de informações, que leva à seleção adversa, é menor para empresas maiores, induzindo-as a contrair mais dívidas (Fama \& French, 2002). No presente trabalho, aceitou-se a posição de Fama e French (2002), esperando-se sinal positivo para esta variável.

Lucratividade. A STT prevê uma relação positiva entre lucratividade e endividamento. A corrente que estuda os custos de falência diz que estes custos sobem, quando o lucro diminui; portanto firmas menos lucrativas ou com maior volatilidade de lucros, tendem a ser menos endividadas. Para a corrente dos 
impostos, quanto mais lucrativa a empresa, mais ela se beneficiaria do escudo fiscal proporcionado pelos juros. A corrente da agência acredita que fluxos de caixa livres, em grandes volumes, acirram o relacionamento conflituoso entre acionistas e gerentes, o que leva tais firmas a contraírem mais dívidas para minorar o problema (Fama \& French, 2003). Para a POT, a melhor opção de financiamento de que dispõe a empresa são os lucros retidos. Este tipo de recurso não produz de nenhum tipo de informação assimétrica ao mercado e pode ser utilizado prontamente para novos projetos. A assimetria de informações, causada pela emissão de ações, é a base da POT. É para fugir do prêmio de seleção adversa que esta assimetria de informações acarreta que as empresas recorrem a recursos próprios como sua principal fonte de financiamento (Myers, 1984). Isso implica taxa de retorno mais elevada, que será exigida por um investidor externo pelo fato de ele não possuir o mesmo nível de informação que os gestores da empresa. A relação entre estas duas variáveis deve ser, portanto, negativa. Uma possibilidade para esta relação inversa, sugerida por Frank e Goyal (2003a, 2003b), é que a lucratividade poderia estar correlacionada com oportunidades de crescimento, o que tornaria difícil para empresas altamente lucrativas oferecerem garantias reais como contrapartida de novos empréstimos. Frank e Goyal (2003b) sugerem que os altos custos de ajustamento levariam a uma relação negativa, sem que isto significasse rejeição da STT. Quando as empresas apresentam lucros, suas dívidas são pagas, mas os elevados custos fixos relacionados com a emissão de novas dívidas as levam a ajustarem sua estrutura de capital apenas periodicamente. Como as dívidas são pagas com o lucro e o ajustamento do nível de alavancagem não ocorre imediatamente, o sinal negativo não iria de encontro à STT. Já Fama e French (2003) vêem esta relação negativa como prova de que a STT está superada e deveria ser repensada.

Dividendos. Segundo a STT, a variável 'Dividendos' é negativamente relacionada com a alavancagem (Frank \& Goyal, 2003a). O motivo vem da teoria da agência, porquanto, para evitar que os dirigentes das empresas criem para si privilégios decorrentes de excesso de caixa, as empresas teriam duas opções: lançar mão de dívidas, o que os obrigaria a serem mais comedidos por terem compromisso com o pagamento dos juros; ou terem uma política agressiva de pagamento de dividendos. Deste modo, endividamento e dividendos são negativamente correlacionados (Jensen, 1986). A POT considera que os dividendos fazem parte do déficit financeiro, sendo, portanto, positivamente correlacionados com o endividamento (Fama \& French, 2002; Frank \& Goyal, 2003a, 2003b).

Déficit Financeiro: para a teoria da agência, o fluxo de caixa livre levaria a maiores necessidades de endividamento. O excesso de caixa faria piorar a já delicada relação entre acionistas e gestores. O endividamento tem o poder de evitar tais possibilidades (Jensen, 1986). Assim, se a POT diz que o excesso de 
caixa é usado para reduzir o endividamento, a corrente da agência da STT prega justamente o contrário.

\section{Resultados}

De uma amostra inicial de 420 empresas não-financeiras com ações listadas nas bolsas BOVESPA e SOMA, entre 1995 e 2002, foi obtido um Panel Data de 2400 observações para os testes do modelo Rajan-Zingales e 2317 para os testes do modelo Frank-Goyal, após ajustes em função de dados incompletos.

\section{Testes Empíricos e Resultados Obtidos - Modelo Rajan-Zingales}

Várias medidas de nível de endividamento foram utilizadas. Dentre elas, apenas as que tinham no denominador o valor do ativo total apresentaram coeficientes estatisticamente relevantes. As que foram medidas em termos de quasi-mercado (valor de mercado das ações somado ao valor contábil da dívida) apresentaram apenas os coeficientes de duas variáveis (logaritmo natural das vendas líquidas e lucratividade) estatisticamente diferentes de zero. As demais medidas mostraram resultados não significativos. As equações originais foram adaptadas para regressões em panel data e testadas sob as seguintes formas:

a) Para o teste de efeitos fixos, apenas com efeitos individuais, sem influência dos efeitos temporais:

$D_{i t}=\alpha+\alpha_{i}$ Empresa $_{i}+\beta_{1} T_{i t}+\beta_{2} M B V_{i t}+\beta_{3} L S_{i t}+\beta_{4} L C R_{i t}+e_{i t}$

b) Para o teste de Efeitos Fixos, com efeitos individuais e efeitos temporais.

$D_{i t}=\alpha+\alpha_{i}$ Empresa $_{i}+\lambda_{t}$ Ano $_{t}+\beta_{1} T_{i t}+\beta_{2} M B V_{i t}+\beta_{3} L S_{i t}+\beta_{4} L C R_{i t}+e_{i t} \quad[10]$

c) Para o teste de efeitos aleatórios.

$D_{i t}=\alpha+\beta_{1} T_{i t}+\beta_{2} M B V_{i t}+\beta_{3} L S_{i t}+\beta_{4} L C R_{i t}+\mu_{i}+v_{i t}$

Na equação [11], o termo errático se apresenta dividido em dois: um relacionado apenas à empresa específica $(\mu \mathrm{i})$ e ortogonal às demais variáveis explicativas e outro específico à observação $\left(v_{\mathrm{it}}\right)$. Para a estimação das regressões utilizou-se a matriz de covariâncias de White, consistente com heteroscedasticidade, tendo em vista a diversidade da amostra. Os resultados encontrados mostram que o modelo mais adequado, de acordo com o teste de Hausman, foi o de efeitos fixos 
individuais. O modelo de efeitos individual e temporal apresentou, em todas as equações testadas, coeficientes nulos para as variáveis dummy temporais.

A Tabela 1 apresenta um resumo dos resultados obtidos com as regressões efetuadas para o modelo RZ. O teste LM indica a melhor adequação de regressões com efeitos fixos ou aleatórios sobre a regressão simples. Valores maiores favorecem efeitos fixos ou aleatórios. O teste de Hausman indica a superioridade de um tipo de efeito sobre o outro, fixos ou aleatórios. Valores maiores favorecem efeitos fixos (Greene, 2003, pp. 283-338).

Tabela 1: Resultados Estimados do Modelo RZ para o Endividamento Contábil

\begin{tabular}{|c|c|c|c|}
\hline MODELO & VARIÁVEIS & LVCAT & LVLAT \\
\hline \multirow{10}{*}{$\begin{array}{l}\text { EFEITOS FIXOS } \\
\text { INDIVIDUAIS }\end{array}$} & TGC / TGL & $-0.8079 *$ & $-0.5358 *$ \\
\hline & & $(0.1187)$ & $(0.1072)$ \\
\hline & MBV & 11.6028 & -10.4540 \\
\hline & & $(63.8140)$ & $(54.9004)$ \\
\hline & LS & $1737.1434 *$ & $1499.1221 *$ \\
\hline & & $(67.1666)$ & $(58.0505)$ \\
\hline & LCR & $-2.8169 *$ & $-2.6563 *$ \\
\hline & & $(0.1197)$ & $(0.1055)$ \\
\hline & R2 & 0.64 & 0.56 \\
\hline & R2 Ajustado & 0.57 & 0.47 \\
\hline \multirow{10}{*}{ EFEITOS ALEATÓRIOS } & TGC / TGL & $\begin{array}{l}-0.3205^{*} \\
(0.1015)\end{array}$ & $\begin{array}{l}-0.1769 * * \\
(0.0802)\end{array}$ \\
\hline & MBV & -9.3906 & -13.2676 \\
\hline & & $(63.4695)$ & $(54.1407)$ \\
\hline & LS & $1813.4099 *$ & $1568.6674 *$ \\
\hline & & $(50.9229)$ & $(42.6717)$ \\
\hline & LCR & $-2.7915^{*}$ & $-2.3365^{*}$ \\
\hline & & $(0.1077)$ & $(0.0919)$ \\
\hline & Constante & $0.9154 *$ & $0.3473^{*}$ \\
\hline & & $(0.0676)$ & $(0.0435)$ \\
\hline & $\mathrm{R} 2$ & ND & ND \\
\hline \multirow{5}{*}{ ESTATÍSTICAS } & LM & 600.41 & 113.62 \\
\hline & Probabilidade & 0.00 & 0.00 \\
\hline & HAUSMAN & 76.52 & 111.70 \\
\hline & Probabilidade & 0.00 & 0.00 \\
\hline & Observações & 2,226 & 2,188 \\
\hline
\end{tabular}

Números entre parênteses são os erros padrões. (*) e (**) indicam significância a $1 \%$ e $5 \%$, respectivamente. LVCAT e LVLAT são o endividamento total e o de longo prazo, respectivamente, em termos contábeis. ND significa não disponível. 
Pela estatística LM e seus respectivos valores-p, pode-se observar que os modelos com efeitos (fixos ou aleatórios) são superiores ao sem efeitos (pooled regression), em todos os casos. Quanto à estatística de Hausman e os respectivos valores-p, os resultados favorecem o modelo com efeitos fixos individuais.

Encontra-se a seguir uma análise dos sinais encontrados para os coeficientes das variáveis independentes.

Tangibilidade dos Ativos. O sinal encontrado foi negativo. Caso se tome como referência Harris e Raviv (1991), este resultado favorece a POT. Caso seja admitido que os ativos permanentes possam efetivamente funcionar como garantia para a contração de novas dívidas, a sua avaliação de mercado raramente corresponde ao seu valor contábil. Quanto maior e mais antiga a empresa, maior tende a ser essa defasagem. No entanto, tamanho e idade são considerados na literatura como positivamente relacionados com o endividamento. Desta forma, empresas com valores cada vez menores em seus ativos fixos apareceriam com valores crescentes de endividamento.

MBV: apresentou-se estatisticamente não significativa. Esta variável tem bastante importância nos testes realizados nos EUA e em outros países desenvolvidos. No Brasil, o pequeno número de negócios realizados diariamente, com poucos atores participantes desse mercado, pode ter diminuído a influência dessa variável no endividamento das empresas.

LS: a proxy para o tamanho das empresas comportou-se como o preconizado pela STT e POT, apresentando uma relação positiva com o nível de endividamento, qualquer que seja ele. Esta relação mostra que efetivamente quanto maior e mais diversificada a empresa, mais facilidade ela tem para contrair dívidas externamente.

LCR: o coeficiente da lucratividade foi sempre significativo e negativo, sinal inverso ao preconizado pela STT. Pela teoria, quanto mais lucrativa a empresa, mais ela tende a contrair dívidas, visando pagar menos imposto de renda. Esta relação negativa foi encontrada em outros trabalhos empíricos sobre o assunto (Booth, Aivazian, Demirguc-Kunt, \& Maksimovic, 2001; Fama \& French, 2002, 2003; Frank \& Goyal, 2003a, 2003b; Lemmon \& Zender, 2002; Rajan \& Zingales, 1995; Sogorb-Mira \& López-Gracia, 2002).

A Tabela 2 apresenta um resumo com o que prediz cada teoria para os sinais das variáveis do modelo Rajan-Zingales. 
Tabela 2: Sinais Esperados versus Sinais Obtidos para o Modelo RZ

\begin{tabular}{|c|c|c|c|c|}
\hline \multirow{2}{*}{$\begin{array}{l}\text { VARIÁVEL } \\
\text { EXPLANATÓRIA }\end{array}$} & \multicolumn{2}{|c|}{ Sinal Esperado } & \multirow{2}{*}{$\begin{array}{c}\text { LVCAT } \\
\text { Sinal Encontrado } \\
\end{array}$} & \multirow{2}{*}{$\begin{array}{c}\text { LVLAT } \\
\text { Sinal Encontrado } \\
\end{array}$} \\
\hline & STT & POT & & \\
\hline TGC / TGL & + & - & - & - \\
\hline MBV & - & - & $\mathrm{N} / \mathrm{S}$ & $\mathrm{N} / \mathrm{S}$ \\
\hline LS & + & + & + & + \\
\hline LCR & + & - & - & - \\
\hline
\end{tabular}

\section{O Modelo Frank-Goyal}

Para o teste do modelo FG, foram utilizados dados de 420 empresas listadas nas bolsas BOVESPA e SOMA, que resultaram em 2317 observações para o período pesquisado (1995 a 2002). Utilizando a metodologia de panel data, foram testadas as equações [6] e [8]:

a) Para o teste de Efeitos Fixos, apenas com efeitos individuais, sem influência dos efeitos temporais:

$\Delta D_{i t}=a+a_{i}$ Empresa $_{i}+b D E F_{i t}+e_{i t}$

$\Delta D_{i t}=a+a_{i}$ Empresa $_{i}+b D I V_{i t}+b I_{i t}+b \Delta W_{i t}-b C_{i t}+e_{i t}$

b) Para o teste de Efeitos Fixos, com efeitos individuais e efeitos temporais:

$\Delta D_{i t}=a+a_{i}$ Empresa $_{i}+d$ Ano $_{t}+b D E F_{i t}+e_{i t}$

$\Delta D_{i t}=a+a_{i}$ Empresa $_{i}+d$ Ano $_{t}+b D I V_{i t}+b I_{i t}+b \Delta W_{i t}-b C_{i t}+e_{i t}$

c) Para o teste de Efeitos Aleatórios.

$\Delta D_{i t}=a+b D E F_{i t}+u_{i}+e_{i t}$

$\Delta D_{i t}=a+b D I V_{i t}+b I_{i t}+b \Delta W_{i t}-b C_{i t}+u_{i}+e_{i t}$ 
Na equação [17], o termo errático está dividido em dois componentes: um relacionado à empresa específica $\left(u_{\mathrm{i}}\right)$ e ortogonal às demais variáveis explicativas e outro específico à observação $\left(e_{\mathrm{it}}\right)$. Tal como no teste do modelo RZ, aqui também o modelo de efeitos fixos individuais e temporais apresentou coeficientes nulos para as variáveis dummy temporais, tendo sido desconsiderados nos resultados finais. A regressão referente à POT foi efetuada de duas maneiras: a primeira tendo como variável explanatória o déficit financeiro agregado; e a segunda, com os componentes desagregados, ambos apresentados na Tabela 3.

Tabela 3: Resultados para o Modelo Frank-Goyal

\begin{tabular}{|c|c|c|c|c|}
\hline & Modelc & Agregado & Modelo I & Desagregado \\
\hline Modelo & Variáveis & Coeficientes & Variáveis & Coeficientes \\
\hline \multirow{9}{*}{$\begin{array}{l}\text { Efeitos Fixos } \\
\text { Individuais }\end{array}$} & DEF & $0,9964 *$ & DIV & $0,9260^{*}$ \\
\hline & & $(0,0016)$ & & $(0,1560)$ \\
\hline & & & INV & $0,9964 *$ \\
\hline & & & & $(0,0012)$ \\
\hline & & & CCL & $0,9791 *$ \\
\hline & & & & $(0,0039)$ \\
\hline & & & CGO & $-0,9661 *$ \\
\hline & & & & $(0,0185)$ \\
\hline & $\mathrm{R}^{2}$ & 0,998 & $\mathrm{R}^{2}$ & 0,998 \\
\hline \multirow{11}{*}{$\begin{array}{l}\text { Efeitos } \\
\text { Aleatórios }\end{array}$} & DEF & $0,9959 *$ & DIV & $1,0171^{*}$ \\
\hline & & $(0,0010)$ & & $(0,1487)$ \\
\hline & Constante & $-0,0364 *$ & INV & $0,9955^{*}$ \\
\hline & & $(0,0056)$ & & $(0,0012)$ \\
\hline & $\mathrm{R}^{2}$ & $\mathrm{ND}$ & CCL & $0,9751 *$ \\
\hline & & & & $(0,0038)$ \\
\hline & & & $\mathrm{CGO}$ & $-0,9545^{*}$ \\
\hline & & & & $(0,0166)$ \\
\hline & & & Constante & $-0,0385^{*}$ \\
\hline & & & & $(0,0057)$ \\
\hline & & & $\mathrm{R}^{2}$ & $\mathrm{ND}$ \\
\hline \multicolumn{5}{|l|}{ Estatísticas: } \\
\hline LM & \multicolumn{2}{|c|}{14,32} & \multicolumn{2}{|c|}{12,09} \\
\hline Probabilidade & \multicolumn{2}{|c|}{0,00} & \multicolumn{2}{|c|}{0,00} \\
\hline HAUSMAN & \multicolumn{2}{|c|}{0,14} & \multicolumn{2}{|c|}{19,79} \\
\hline Probabilidade & \multicolumn{2}{|c|}{$\frac{0,71}{2017}$} & \multicolumn{2}{|c|}{0,00} \\
\hline Observações & \multicolumn{2}{|c|}{2317} & \multicolumn{2}{|c|}{2317} \\
\hline
\end{tabular}

Números entre parênteses são os erros padrões. Todos os coeficientes são estatisticamente significativos a $1 \%$. ND significa não disponível. 
O resultado esperado para a variável explanatória agregada é que o seu coeficiente seja bastante próximo da unidade, para o modo forte da POT. O resultado encontrado foi altamente favorável a esta teoria. Em todos os modelos (efeitos fixos individuais e efeitos aleatórios), o valor do coeficiente do déficit foi bastante próximo da unidade. $\mathrm{O}$ valor do $\mathrm{R}^{2}$ foi também bastante elevado, o que sugere que as empresas amostradas se comportam conforme a POT. Os resultados mostram que as empresas emitiram novas dívidas, quando o valor de seus investimentos foi maior que o fluxo de caixa gerado; e resgataram suas dívidas, quando o fluxo de caixa foi superior a suas necessidades de investimento. A emissão de novas ações quase não foi utilizada. A estatística LM mostra que para ambas as equações, o modelo a ser considerado deve ser aquele com efeitos (fixos ou aleatórios) em detrimento daquele sem efeitos (pooled regression). $\mathrm{O}$ teste de Hausman mostra dois resultados distintos. Quando o déficit é utilizado na regressão de modo agregado, o melhor modelo é o dos efeitos aleatórios. Quando é feita a desagregação, o modelo com efeitos fixos se mostra superior. Frank e Goyal (2003b) sugeriram ser importante a desagregação dos componentes do déficit financeiro, para que se possa analisar a influência de cada um sobre a variação do endividamento. Essa desagregação não é exigência da POT; mas, quando os componentes do déficit são avaliados separadamente, o comportamento das variáveis que compõem o déficit pode ser estudado mais profundamente sob a ótica da STT. Em relação a um dos componentes do déficit financeiro, a variável que mede o pagamento de dividendos (DIV), sinal encontrado em todas as regressões de todos os modelos testados, confirma o que prediz a POT, i.e., relação positiva entre a variação no endividamento em função do pagamento de dividendos. Fama e French (2002) sugeriram que as empresas tendem a ajustar o pagamento de dividendos, para que estes caibam em seus recursos internos, sem que seja necessário recorrerem a novas dívidas. Quanto às demais variáveis que compõem o déficit financeiro, merece destaque a que mede o fluxo de caixa livre, $\mathrm{C}_{\mathrm{it}}$. Conforme discutido anteriormente, esta variável tem comportamento previsto de modo díspar pelas teorias. Este fluxo de caixa é justamente o apontado por Jensen (1986) como motivo de maiores conflitos de agência. Como no caso da Lucratividade, o sinal encontrado no presente trabalho para o fluxo de caixa também é altamente favorável à POT.

A exemplo do que foi apresentado para o modelo RZ, e para que se possa fazer comparação entre os resultados dos dois modelos, a Tabela 4 apresenta os sinais esperados e os sinais obtidos empiricamente para os coeficientes das variáveis explanatórias de acordo com cada uma das teorias. 
Tabela 4: Sinais Esperados versus Sinais Obtidos para os Testes do Modelo FG Desagregado

\begin{tabular}{l|c|c|c}
\hline VARIÁVEL & \multicolumn{2}{|c|}{ Sinal Esperado } & Sinal Encontrado \\
\cline { 2 - 3 } EXPLANATÓRIA & STT & POT & \\
\hline DIV & - & + & + \\
INV & + & + & + \\
CCL & + & + & + \\
CGO & + & - & - \\
\hline
\end{tabular}

Para que o teste da POT seja completo, não basta analisar a hipótese de que os coeficientes angulares não são nulos. É preciso também que se determine se eles são iguais à unidade (ou pelo menos bastante próximos a ela) ou não. Caso positivo, a forma forte da POT pode ser aceita; caso contrário, se o valor encontrado for diferente, mas próximo à unidade $(0,9$, por exemplo), a forma semiforte é a predominante. A hipótese nula testada foi que $\beta=1$, contra a hipótese alternativa de que $\beta<1$, para a equação [6] e para a equação [8], para níveis de confiança de $1 \%$ e $5 \%$. Os resultados obtidos estão na Tabela 5 .

\section{Tabela 5: Intervalos de Confiança para os Coeficientes das Equações [6] e [8]}

\begin{tabular}{l|l|c|c|c|c}
\hline \multicolumn{2}{l|}{ Nível de Significância } & \multicolumn{2}{|c|}{$1 \%$} & \multicolumn{2}{c}{$5 \%$} \\
\hline \multirow{2}{*}{ Variável } & Intervalo & Efeitos Fixos & Efeitos Aleatórios & Efeitos Fixos & Efeitos Aleatórios \\
\hline \multirow{2}{*}{ DEF } & inferior & 0.99 & 0.99 & 0.99 & 0.99 \\
\cline { 2 - 6 } & Superior & 1.00 & 1.00 & 1.00 & 1.00 \\
\hline \multirow{2}{*}{ DIV } & inferior & 0.69 & 0.79 & 0.73 & 0.83 \\
\cline { 2 - 6 } & Superior & 1.17 & 1.25 & 1.13 & 1.21 \\
\hline \multirow{2}{*}{ INV } & inferior & 0.99 & 0.99 & 0.99 & 0.99 \\
\cline { 2 - 6 } & Superior & 1.00 & 1.00 & 1.00 & 1.00 \\
\hline \multirow{2}{*}{ CCL } & inferior & 0.97 & 0.97 & 0.97 & 0.97 \\
\cline { 2 - 6 } & Superior & 0.99 & 0.98 & 0.98 & 0.98 \\
\hline \multirow{2}{*}{ CGO } & inferior & $(0.99)$ & $(0.98)$ & $(0.99)$ & $(0.98)$ \\
\cline { 2 - 6 } & Superior & $(0.94)$ & $(0.93)$ & $(0.94)$ & $(0.93)$ \\
\hline \multirow{2}{*}{ Constante } & inferior & & $(0.05)$ & & $(0.05)$ \\
\cline { 2 - 6 } & Superior & & $(0.03)$ & & \\
\hline
\end{tabular}

Comparando os valores obtidos para os coeficientes angulares, relatados na Tabela 3 , com os intervalos de confiança construídos na Tabela 5, pode-se observar que todos os coeficientes angulares estimados estão dentro dos intervalos de confiança, tanto para $1 \%$ quanto para 5\% de significância, de modo que as hipóteses $\mathrm{H}_{0}$ de que os verdadeiros parâmetros da população são iguais à unidade não podem ser rejeitadas. No entanto, observa-se que o valor de $-0,0385$, obtido para a constante no modelo de efeitos aleatórios (vide Tabela 5), se situa fora dos intervalos de confiança, a $1 \%$ e a $5 \%$ de significância, construídos para esse coeficiente, levando à rejeição da hipótese 
nula de que a constante é igual a zero. Em conjunto, os testes levam à aceitação de que a corrente que melhor explica a estrutura de capital das empresas brasileiras, durante o período de 1995 a 2002, é a POT em sua forma semiforte.

\section{Conclusões}

A análise dos resultados leva à conclusão de que a POT foi a corrente dominante na determinação da estrutura de capital das empresas da amostra. Para as variáveis testadas no modelo RZ, a tangibilidade dos ativos e a lucratividade comportaram-se conforme previsto pela POT e não pela STT. Como estas variáveis são consideradas peças-chave na aceitação de uma teoria em detrimento da outra (Fama \& French, 2003; Frank \& Goyal, 2003b), os resultados encontrados favorecem a POT. O comportamento previsto para o logaritmo natural das vendas é o mesmo, sob ambas as teorias, e o resultado encontrado está de acordo com o esperado. Já o 'Índice Valor de Mercado sobre Valor Patrimonial', considerado importante nas pesquisas realizadas nos EUA, mostrou-se estatisticamente não-significativo. Frank e Goyal (2003b) consideraram a variável 'tangibilidade dos ativos' como o fator fundamental para determinar a superioridade de uma ou outra teoria. Já para Fama e French (2003) o comportamento da 'lucratividade' é que deveria ser visto como motivo para o descarte incondicional da STT. Como o sinal encontrado para estas duas variáveis foi o previsto pela POT e não pela STT, concluiu-se que aquela foi a teoria que melhor explicou a determinação da estrutura de capital das empresas brasileiras listadas em bolsa no período. Se o sinal obtido para a variável 'tangibilidade dos ativos' pode ser atribuído à ausência da correção monetária nos balanços aliado a altos índices de inflação, o sinal encontrado para a 'lucratividade' pode ser considerado como ponto fundamental no descarte da STT para a amostra em estudo. A STT prevê que o nível de endividamento aumenta com os lucros das empresas, exatamente o oposto do que prevê a POT. As características da economia brasileira, com taxas de juros reais elevadas e escassez de oferta de crédito para financiamentos e empréstimos de longo prazo, levaria as empresas brasileiras a evitarem o uso de capital de terceiros, quando há recursos disponíveis gerados internamente. Esses são normalmente usados para o resgate de dívidas, que é exatamente o que prevê a POT e em linha com os resultados encontrados.

A POT estabelece que o déficit financeiro é coberto pela variação no endividamento, permitindo a emissão de novas ações apenas em casos excepcionais. O modelo FG pressupõe que o coeficiente angular da variável que mede o déficit financeiro é igual ou bastante próximo da unidade, para que a forma forte da POT seja aceita. Assim, o teste mais importante foi o que determinou o valor deste coeficiente. Entretanto, para que a POT fosse aceita em sua forma forte, seria 
necessário que o intercepto fosse igual a zero, significando que a variação no endividamento seria exatamente proporcional ao déficit do período. Tal fato não ocorreu, pois a hipótese de que o intercepto é nulo foi rejeitada. Assim, o resultado obtido no presente trabalho foi favorável à POT em sua forma semiforte. Quanto à análise comparativa dos resultados obtidos, ela pôde ser feita apenas para a forma desagregada do modelo FG. As variáveis controversas, sob as duas teorias, foram os dividendos e o fluxo de caixa livre. Aqui também, os resultados obtidos foram totalmente favoráveis à POT. A relação positiva encontrada entre os dividendos e a variação no endividamento é contrária à idéia de que os dividendos poderiam substituir o endividamento na resolução de conflitos de agência. A interpretação do sinal da variável que mediu o fluxo de caixa livre é a mesma que foi dada à variável 'lucratividade', fortalecendo a POT ao mesmo tempo que enfraqueceu a STT.

A conclusão final é de que as empresas brasileiras não estabelecem meta para a estrutura de capital e procuram atingi-la ao longo do tempo. Pelo contrário, a estrutura de capital das empresas brasileiras é estabelecida como resultado de uma hierarquia de financiamento, cuja prioridade máxima são os recursos gerados internamente, seguidos pelo endividamento e, em última instância, pela emissão de ações. Na verdade, a quase aceitação da POT em sua forma forte mostrou que, na média, a emissão de ações é muito pequena em relação às outras duas formas de financiamento.

\section{Artigo recebido em 07.12.2004. Aprovado em 16.03.2005.}

\section{ReferênCIas Bibliográficas}

Baltagi, B. H. (2001).

Econometric analysis of panel data. West Sussex, UK: John Wiley.

Booth, L.,

Aivazian, V.,

Demirguc-Kunt, A., \&

Maksimovic, V. (2001).

Capital structures in developing countries. The Journal of Finance, 56(1), 87-130.
Breusch, T. S., \&

Pagan, A. R. (1980).

The lagrange multiplier test and its application to model specification in econometrics. Review of Economic Studies, 47(1), 239-254.

Chirinko, R. S., \&

Singha, A. R. (2000).

Testing static tradeoff against pecking order models of capital structure: a critical comment. Journal of Financial Economics, 58(3), 417425. 
Fama, E. F., \&

French, K. R. (2002).

Testing trade-off and pecking order predictions about dividends and debt. Review of Financial Studies, 15(1), 1-33.

Fama, E. F., \&

French, K. R. (2003).

Financing decisions: who issues stock? [SSRN Working Paper Series $\mathrm{n}^{\circ}$ 429640], Social Science Eletronic Publishing, Rochester, New York, USA.

Famá, R.,

Barros, L., \&

Silveira, A. (2001).

A estrutura de capital é relevante? Novas evidências a partir de dados Norte-Americanos e LatinoAmericanos. Caderno de Pesquisas em Administração, 8(2), 71-84.

Famá, R., \&

Grava, J. W. (2000).

Teoria da estrutura de capital - As discussões persistem. Caderno de Pesquisas em Administração, 1(11), 27-36.

Famá, R., \&

Melher, S. (1999).

Estrutura de capital na América Latina: existiria uma correlação com o lucro das empresas? Recuperado em 15 abril, 2004, de http:// www.fia.com.br/labfin/ pesquisa/ artigos/arquivos/1.pdf

Frank, M. Z., \&

Goyal, V. K. (2003a).

Capital structure decisions. [SSRN Working Paper Series no 396020], Social Science Eletronic Publishing, Rochester, New York, USA.
Frank, M. Z., \&

Goyal, V. K. (2003b).

Testing the pecking order theory of capital structure. Journal of Financial Economics, 67(2), 217-248.

Greene, W. H. (2003).

Econometric analysis (5th ed.). Upper Saddle River, NJ: Prentice Hall.

Harris, M., \&

Raviv, A. (1991).

The theory of capital structure. The Journal of Finance, 46(1), 297-355.

Hausman, J. A. (1978).

Specification tests in econometrics. Econometrica, 46(6), 1215-1271.

Jensen, M. C. (1986).

Agency costs of free cash flow, corporate finance, and takeovers. American Economic Review, 76(2), 323-329.

Jensen, M. C., \&

Meckling, W. (1976).

Theory of the firm: managerial behavior, agency costs, and capital structure. Journal of Financial Economics, 3(4), 305-360.

Lemmon, M. L., \&

Zender, J. (2002).

Debt capacity and tests of capital structure theories. [SSRN Working Paper Series ${ }^{\circ}$ 334780], Social Science Eletronic Publishing, Rochester, New York, USA.

Marsh, P. (1982).

The choice between equity and debt: an empirical study. The Journal of Finance, 37(1), 121-144. 
Myers, S. (1977).

Determinants of corporate borrowing. Journal of Financial Economics, 5(2), 147-175.

Myers, S. (1984).

The capital structure puzzle. The Journal of Finance, 39(3), 575-592.

Myers, S., \&

Majluf, N. (1984).

Corporate financing and investment decisions when firms have informations that investors do not have. Journal of Financial Economics, 13(2), 187-221.

Rajan, R. G., \&

Zingales, L. (1995).

What do we know about capital structure? Some evidence from international data. The Journal of Finance, 50(5), 1421-1460.

Ross, S. (1977).

The determination of financial structure: the incentive signaling approach. Bell Journal of Economics, 8(1), 23-40.

Shyam-Sunder, L., \&

Myers, S. C. (1999).

Testing static tradeoff against pecking order models of capital structure. Journal of Financial Economics, 51(2), 219-244.

Sogorb-Mira, F., \&

López-Gracia, J. (2002).

Pecking order versus trade-off: an empirical approach to the small and medium enterprise capital structure. [Working Paper Series n ${ }^{\circ}$ 393160], Social Science Eletronic Publishing, Rochester, New York, USA.

Titman, S., \&

Wessels, R. (1988).

The determinants of capital structure choice. The Journal of Finance, 43(1), 1-19.

Watson, R., \&

Wilson, N. (2002).

Small and medium size enterprise financing: a note on some of the empirical implications of a pecking order. Journal of Business Finance \& Accounting, 29(3/4), 557-578.

White, H. (1980).

A heteroskedasticity-consistent covariance matrix estimator and a direct test for heteroskedasticity. Econometrica, 48(4), 817-838. 
